Bull. Chem. Soc. Ethiop. 2013, 27(3), 367-376.

Printed in Ethiopia

DOI: http://dx.doi.org/10.4314/bcse.v27i3.5

ISSN 1011-3924

(c) 2013 Chemical Society of Ethiopia

\title{
STABILITY OF BINARY COMPLEXES OF L-ASPARTIC ACID IN DIOXAN-WATER MIXTURES
}

\author{
Routh Swaroopa Rani and Gollapalli Nageswara Rao* \\ Department of Inorganic and Analytical Chemistry, School of Chemistry, Andhra University, \\ Visakhapatnam-530003, India
}

(Received September 19, 2012; revised June 24, 2013)

\begin{abstract}
Speciation of binary complexes of $\mathrm{Co}(\mathrm{II}), \mathrm{Ni}(\mathrm{II})$ and $\mathrm{Cu}(\mathrm{II})$ with $\mathrm{L}$-aspartic acid in $(0-60 \% \mathrm{v} / \mathrm{v})$ 1,4-dioxan (Dox)-water mixtures was studied $\mathrm{pH}$ metrically at $303 \pm 0.1 \mathrm{~K}$ and at an ionic strength of $0.16 \mathrm{M}$. The models contained $\mathrm{ML}, \mathrm{ML}_{2}, \mathrm{ML}_{2} \mathrm{H}_{2}, \mathrm{ML}_{2} \mathrm{H}_{3}$ and $\mathrm{ML}_{2} \mathrm{H}_{4}$ species. The trend in the variation of stability constants with Dox content was explained on the basis of electrostatic and non-electrostatic forces. Distribution of the species with $\mathrm{pH}$ at different compositions of Dox-water media was also presented.
\end{abstract}

KEY WORDS: Binary complexes, Stability constants, Aspartic acid, Speciation, Dioxan

\section{INTRODUCTION}

1,4-Dioxan (Dox) is cyclic ether that exists at room temperature as a colorless liquid with a faint, pleasant ethereal odour. It is miscible with water, oils, and most organic solvents, including aromatic hydrocarbons. It is highly flammable and may form dangerous peroxides with prolonged exposure to air and sunlight, especially in the presence of moisture. L-Aspartic acid (Asp) forms complexes with almost all the metal ions through its three binding sites. Chelation through the amino and $\alpha$-carboxylate groups occurs readily, and study of metal binding has been devoted to attempts to deduce whether side chain carboxylates are also coordinated to the metal ion. Three chelate rings are formed, when Asp is tridentate ligand.

Simultaneous equilibria involving a variety of metal ions and amino acids are important in biological fluids [1-6]. Hence, chemical speciation of ligands with metal ions has been studied in this laboratory [7-13]. Speciation studies of aspartic acid with various metal ions in different media were reported earlier $[14,15]$.

Several literature reports have been devoted to the study of stability constants of metal-Asp complexes. Lumb and Martell [16] carried out potentiometric studies on the complex formation with $\mathrm{Mg}(\mathrm{II}), \mathrm{Ca}(\mathrm{II}), \mathrm{Pd}(\mathrm{II})$ and $\mathrm{Te}(\mathrm{I})$. Vadi et al. [17] studied $\mathrm{V}(\mathrm{IV})$ complexes potentiometrically. Stability constants of $\mathrm{Mn}$ (II) and $\mathrm{Cd}(\mathrm{II})$ were studied by Gianguzza et al. [18]. Potentiometric study of $\mathrm{Fe}(\mathrm{II})$ and $\mathrm{Zn}$ (II) was carried out by Ritsma [19], Maker et al. [20], Gergely and Farkas [21]. Co(II) complexes were studied by Gergely et al. [22]. Ni(II) complexes were studied by Maker et al. [20] and Gergely et al. [23]. Voltametric study of Sr(II) complexes was carried out by Heijne and van der Linden [24]. Ba(II) complexes were studied by Sarin and Munshi [25] potentiometrically. Stability constants of $\mathrm{Pb}$ (II) complexes were studied by Kulba et al. [26] potentiometrically and Kodama and Takahashi [27] polarographically.

The equilibrium studies involving various metals and Asp were not exhaustive and many of these studies were performed in limited concentration ranges of the ingredients. Further, there are some differences in the nature of the reported species. There are several instances where different authors reported different species for the same system under comparable conditions. Probably this may be attributed to the nature of probes, the errors associated with the probing techniques or the inadequacies associated with the modelling strategies.

*Corresponding author. E-mail: gollapallinr@yahoo.com 
The stability constants of M(II)-Asp complexes with different electrolytic background reported in literature are recorded in Table 1. Hence, chemical speciation of their binary complexes is reported in the present communication.

Table 1. Stability constants of M(II)-Asp complexes reported in the literature. (Temp. $=303.0 \mathrm{~K}$, ionic strength $=0.16 \mathrm{M})$.

\begin{tabular}{|c|c|c|c|c|c|c|c|}
\hline \multirow{2}{*}{ Metal } & \multicolumn{4}{|c|}{$\log \beta$} & \multirow{2}{*}{$\begin{array}{c}\text { Ionic strength } \\
\text { (M) }\end{array}$} & \multirow{2}{*}{ Method } & \multirow{2}{*}{ Ref. } \\
\hline & ML & $\mathrm{ML}_{2}$ & MLH & $\mathrm{ML}_{2} \mathrm{H}_{2}$ & & & \\
\hline $\operatorname{Mg}(\mathrm{II})$ & 2.43 & - & - & - & 0.1 & Potentiometry & 16 \\
\hline $\mathrm{Ca}(\mathrm{II})$ & 1.60 & - & - & - & 0.1 & , & 16 \\
\hline $\mathrm{Pd}(\mathrm{II})$ & 1.48 & - & - & - & 0.7 & , & 16 \\
\hline $\mathrm{Te}(\mathrm{I})$ & 1.14 & - & - & - & - & , & 16 \\
\hline $\mathrm{V}(\mathrm{IV})$ & 8.39 & 6.05 & - & - & 0.1 & , & 17 \\
\hline $\mathrm{Mn}(\mathrm{II})$ & 3.74 & - & 12.82 & 25.15 & 0.1 & , & 18 \\
\hline $\mathrm{Cd}(\mathrm{II})$ & 10.55 & 7.7 & - & - & 0.1 & , & 18 \\
\hline $\mathrm{Fe}(\mathrm{II})$ & 9.08 & 7.17 & - & - & 0.1 & , & 19 \\
\hline \multirow[t]{4}{*}{$\mathrm{Zn}$ (II) } & 8.94 & 6.95 & 12.59 & - & 0.1 & , & 19 \\
\hline & 6.04 & 4.09 & 11.88 & 10.41 & 0.15 & , & 20 \\
\hline & 5.66 & 4.48 & 10.78 & - & 0.3 & , & 21 \\
\hline & 5.73 & 4.47 & - & - & 0.2 & 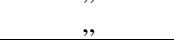 & 21 \\
\hline $\mathrm{Co}$ (II) & 5.94 & 4.29 & - & - & 1.0 & , & 22 \\
\hline \multirow[t]{2}{*}{$\mathrm{Ni}(\mathrm{II})$} & 7.14 & 5.29 & 1.19 & - & 0.2 & 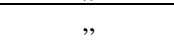 & 23 \\
\hline & 7.16 & 5.24 & - & - & 0.1 & , & 20 \\
\hline $\mathrm{Sr}(\mathrm{II})$ & 5.45 & 8.95 & 10.25 & - & 1.0 & Voltametry & 25 \\
\hline In(III) & 4.70 & 3.4 & - & - & 0.1 & Potentiometry & 25 \\
\hline $\mathrm{Ba}(\mathrm{II})$ & - & - & 12.96 & 22.66 & 0.1 & , & 25 \\
\hline $\mathrm{Pb}(\mathrm{II})$ & 1.14 & - & - & - & 0.1 & , & 26 \\
\hline
\end{tabular}

\section{EXPERIMENTAL}

$0.05 \mathrm{M}$ solution of L-aspartic acid (Merck, India) was prepared in triple-distilled water by maintaining $0.05 \mathrm{M}$ hydrochloric acid concentration to increase the solubility. 1,4-Dioxan (Finar, India) was used as received. 0.2 M hydrochloric acid (Qualigens, India) was prepared. 2.0 M sodium chloride (Qualigens, India) was prepared to maintain the ionic strength in the titrand. $0.05 \mathrm{M}$ solutions of $\mathrm{Co}(\mathrm{II}), \mathrm{Ni}(\mathrm{II})$ and $\mathrm{Cu}(\mathrm{II})$ chlorides were prepared by dissolving G.R. grade (E-Merck, Germany) salts in triple distilled water maintaining $0.05 \mathrm{M}$ hydrochloric acid to suppress the hydrolysis of metal salts. $0.4 \mathrm{M}$ sodium hydroxide (Qualigens, India) was prepared. Acid and alkali solutions were standardized by volumetric and $\mathrm{pH}$ metric methods. The strength of mineral acid in metal ion and ligand solutions was determined using the Gran plot method $[28,29]$. To assess the errors that might have crept into the determination of the concentrations, the data were subjected to analysis of variance of one way classification (ANOVA) [30].

\section{Procedure}

An ELICO (Model LI-120) $\mathrm{pH}$ meter of 0.01 readability in conjunction with a glass combination $\mathrm{pH}$ electrode was used to monitor the changes in the hydrogen ion concentration. The electrode was immersed in a well stirred mixture of required composition of Dox-water mixtures $(0.0-60.0 \% \mathrm{v} / \mathrm{v})$ for several days. The effect of variations in asymmetry potential, liquid junction potential, activity coefficient, sodium ion error and dissolved carbon dioxide on the response of glass electrode cannot be calculated in $\mathrm{pH}$ metric methods. Hence the difference 
between the experimentally observed $\mathrm{pH}$ in solvent medium and the $\mathrm{pH}$ calculated based on the concentrations of the ingredients is used as factor that accounts for all the above parameters. This factor is named as correction factor in complex equilibria [31]. The correction factor is subtracted from $\mathrm{pH}$ meter dial reading. The computer program SCPHD [32] was used to calculate the correction factor.

For the determination of stability constants of binary species, initially strong acid was titrated against the alkali at regular intervals to check the complete equilibration of the glass electrode. Before each titration in Dox-water mixtures, the electrode was preconditioned for at least 1 hour in a solution of identical composition as that of the titrand. The titrand consisted of approximately $1 \mathrm{mmol}$ mineral acid in a total volume of $50 \mathrm{~mL}$. All the titrations were performed in medium containing varying concentrations of Dox-water mixture $\mathrm{pH}$ metrically at 303.0 $\pm 0.1 \mathrm{~K}$. In each of the titrations, titrations with different metal-to-ligand ratios (1.0:2.5, 1.0:3.75 and 1.0:5.0) were carried out with $0.4 \mathrm{M} \mathrm{NaOH}$.

\section{Modelling strategy}

MINIQUAD75 [33] was used to calculate the stability constants from $\mathrm{pH}$ metric titration data. The correction factor and protonation constants of Asp [34] were fixed during the refinement of binary systems. The variation of stability constants with the dielectric constant of the medium was analyzed on the basis of electrostatic/non-electrostatic, solute-solute and solute-solvent interactions. The protonation constants of Asp determined in the present study are compared with the literature values (Table 2).

Table 2. Comparison of protonation constants of aspartic acid reported in literature with the present study.

\begin{tabular}{|c|c|c|c|c|c|}
\hline \multirow{2}{*}{ Medium } & \multicolumn{3}{|c|}{$\log \beta$} & \multirow{2}{*}{ Ionic strength (M) } & \multirow{2}{*}{ Ref. } \\
\hline & 011 & 012 & 013 & & \\
\hline Aqueous & 9.85 & 13.56 & 15.49 & 0.16 & 7 \\
\hline Aqueous & 9.67 & 13.65 & 15.53 & 0.16 & 9 \\
\hline Aqueous & 7.42 & 10.41 & 12.88 & 0.2 & 35 \\
\hline Aqueous & 9.60 & 13.25 & 15.13 & 0.1 & 36 \\
\hline \multicolumn{6}{|l|}{$\% \mathrm{v} / \mathrm{v}$ Dox } \\
\hline 0.0 & 9.83 & 13.54 & 15.33 & 0.16 & 34 \\
\hline 10.0 & 9.91 & 13.78 & 15.79 & 0.16 & 34 \\
\hline 20.0 & 9.98 & 13.98 & 16.33 & 0.16 & 34 \\
\hline 30.0 & 10.16 & 14.32 & 16.73 & 0.16 & 34 \\
\hline 40.0 & 10.28 & 14.65 & 17.33 & 0.16 & 34 \\
\hline 50.0 & 10.20 & 14.73 & 17.48 & 0.16 & 34 \\
\hline 60.0 & 10.26 & 15.10 & 18.23 & 0.16 & 34 \\
\hline
\end{tabular}

\section{RESULTS AND DISCUSSION}

The results of the best fit models that contain the stoichiometry of the complex species and their overall stability constants along with some of the important statistical parameters are given in Table 3. Very low standard deviation in the overall stability constants $(\log \beta)$ signifies the precision of these constants. The small values of $U$ (sum of squares of deviations in concentrations of ingredients at all experimental points) corrected for degrees of freedom and standard deviation for the systems are validated by residual analysis. 
Table 3. Parameters of best fit chemical models of $\mathrm{Co}(\mathrm{II}), \mathrm{Ni}(\mathrm{II})$ and $\mathrm{Cu}$ (II) complexes of Asp in Dox-water mixtures.

\begin{tabular}{|c|c|c|c|c|c|c|c|c|c|c|c|c|}
\hline \multirow{2}{*}{$\begin{array}{c}\text { Dox } \\
\% \\
\mathrm{v} / \mathrm{v}\end{array}$} & \multicolumn{5}{|c|}{$\log \beta_{\mathrm{mlh}}(\mathrm{SD})$} & \multirow{2}{*}{$\begin{array}{c}\mathrm{pH}- \\
\text { range }\end{array}$} & \multirow[t]{2}{*}{ NP } & \multirow{2}{*}{\begin{tabular}{|c|}
$\mathrm{U}_{\text {cor }}$ \\
$\mathrm{x} 10^{8}$
\end{tabular}} & \multirow[t]{2}{*}{$\chi^{2}$} & \multirow{2}{*}{\begin{tabular}{|c|} 
Skew- \\
ness
\end{tabular}} & \multirow{2}{*}{$\begin{array}{c}\text { Kurt- } \\
\text { osis }\end{array}$} & \multirow[t]{2}{*}{ R-factor } \\
\hline & $\mathrm{ML}$ & $\mathrm{ML}_{2}$ & $\mathrm{ML}_{2} \mathrm{H}_{2}$ & $\mathrm{ML}_{2} \mathrm{H}_{3}$ & $\mathrm{ML}_{2} \mathrm{H}_{4}$ & & & & & & & \\
\hline \multicolumn{13}{|c|}{$\mathrm{Co}$ (II) } \\
\hline 00.0 & $6.48(14)$ & $10.44(15)$ & $25.1(12)$ & $29.36(14)$ & $33.25(10)$ & $3.0-10.5$ & 35 & 2.15 & \begin{tabular}{|l|}
12.10 \\
\end{tabular} & -0.06 & 4.05 & \begin{tabular}{|l|}
0.0112 \\
\end{tabular} \\
\hline 10.0 & $7.21(11)$ & \begin{tabular}{|l|}
$12.17(13)$ \\
\end{tabular} & $25.82(12)$ & $29.82(15)$ & $33.65(11)$ & $2.0-9.0$ & 14 & 0.45 & \begin{tabular}{|l|l|}
19.71 \\
\end{tabular} & 1.53 & 7.63 & \begin{tabular}{|l|}
0.0072 \\
\end{tabular} \\
\hline 20.0 & $7.30(7)$ & 12.04(11) & $25.23(6)$ & \begin{tabular}{|l|}
$29.26(8)$ \\
\end{tabular} & \begin{tabular}{|l|}
$33.03(5)$ \\
\end{tabular} & $2.0-8.5$ & 66 & 0.71 & 29.48 & -0.20 & 5.95 & \begin{tabular}{|l|}
0.0039 \\
\end{tabular} \\
\hline 30.0 & $7.51(4)$ & \begin{tabular}{|l|}
$12.88(6)$ \\
\end{tabular} & \begin{tabular}{|l|}
$25.26(5)$ \\
\end{tabular} & \begin{tabular}{|l|}
$29.34(7)$ \\
\end{tabular} & \begin{tabular}{|l|}
$33.01(8)$ \\
\end{tabular} & $2.5-8.0$ & 44 & 0.22 & 35.22 & -0.45 & \begin{tabular}{|l|}
0.27 \\
\end{tabular} & \begin{tabular}{|l|}
0.0028 \\
\end{tabular} \\
\hline 40.0 & $7.75(4)$ & $13.46(7)$ & 25.21(8) & $29.68(8)$ & 33.08(15) & $2.2-8.5$ & 90 & 0.65 & 52.79 & 0.27 & 4.21 & 0.0043 \\
\hline 50.0 & 7.84(3) & $13.74(5)$ & $25.23(6)$ & $29.33(13)$ & $33.48(9)$ & $2.5-7.5$ & 74 & 0.36 & 50.00 & -0.77 & 6.63 & 0.0036 \\
\hline 60.0 & $8.71(6)$ & $15.03(8)$ & 26.01(17) & $30.80(10)$ & $34.95(8)$ & $2.5-7.5$ & 76 & 1.04 & 23.09 & -0.60 & 4.07 & 0.0061 \\
\hline \multicolumn{13}{|c|}{$\mathrm{Ni(II)}$} \\
\hline 00.0 & 7.61(4) & $13.06(8)$ & $24.33(6)$ & $27.69(13)$ & $30.96(11)$ & $2.0-8.0$ & 59 & \begin{tabular}{|l|}
0.37 \\
\end{tabular} & \begin{tabular}{|l|}
27.43 \\
\end{tabular} & -0.36 & \begin{tabular}{|l|}
4.36 \\
\end{tabular} & \begin{tabular}{|l|}
0.0029 \\
\end{tabular} \\
\hline 10.0 & $8.05(12)$ & 13.95(13) & $24.53(22)$ & $27.9(44)$ & $31.44(49)$ & $2.5-9.0$ & 33 & 0.28 & 19.06 & -0.01 & 3.65 & \begin{tabular}{|l|}
0.0036 \\
\end{tabular} \\
\hline 20.0 & $8.32(6)$ & $14.15(10)$ & 24.99(11) & $28.85(11)$ & $32.34(15)$ & $2.0-7.0$ & 65 & 0.21 & 51.93 & -0.31 & 5.95 & 0.0059 \\
\hline 30.0 & $8.47(3)$ & $14.83(6)$ & 25.12(9) & $29.06(11)$ & $32.27(15)$ & $2.5-7.5$ & 100 & 0.50 & 69.87 & -0.34 & 6.16 & 0.0034 \\
\hline 40.0 & $8.99(5)$ & $15.67(9)$ & $25.78(20)$ & $29.96(14)$ & $33.71(13)$ & $2.5-8.5$ & 71 & 1.14 & 34.92 & -0.07 & 4.93 & 0.0066 \\
\hline 50.0 & $8.80(5)$ & $15.78(7)$ & $25.62(14)$ & - & $33.13(22)$ & $2.0-8.0$ & 109 & 1.11 & 61.43 & -1.67 & 10.32 & 0.0051 \\
\hline 60.0 & $9.21(3)$ & $16.67(4)$ & $26.82(6)$ & $30.48(6)$ & $34.87(8)$ & $2.5-8.0$ & 45 & 1.61 & 7.99 & -0.15 & 3.08 & \begin{tabular}{|l|}
0.0045 \\
\end{tabular} \\
\hline \multicolumn{13}{|c|}{$\mathrm{Cu}(\mathrm{II})$} \\
\hline 00.0 & $9.15(5)$ & $16.20(7)$ & $25.16(10)$ & $28.22(13)$ & 31.03(17) & $1.9-9.5$ & 31 & 0.24 & 28.72 & -1.67 & 15.11 & 0.0025 \\
\hline 10.0 & $9.56(6)$ & $16.97(8)$ & $25.60(13)$ & \begin{tabular}{|l|}
$29.03(9)$ \\
\end{tabular} & 31.72(27) & $2.6-8.5$ & 58 & 0.38 & \begin{tabular}{|l|}
8.16 \\
\end{tabular} & 0.07 & \begin{tabular}{|l|}
3.51 \\
\end{tabular} & \begin{tabular}{|l|}
0.0043 \\
\end{tabular} \\
\hline 20.0 & $10.31(4)$ & \begin{tabular}{|l|}
$17.50(5)$ \\
\end{tabular} & $26.10(16)$ & $30.13(3)$ & \begin{tabular}{|l|}
$32.80(9)$ \\
\end{tabular} & $2.3-7.5$ & 55 & 0.18 & \begin{tabular}{|l|}
6.98 \\
\end{tabular} & 0.01 & 2.97 & 0.0022 \\
\hline 30.0 & $10.46(5)$ & \begin{tabular}{|l|}
$16.94(9)$ \\
\end{tabular} & $26.60(18)$ & $30.70(4)$ & $33.60(5)$ & $2.0-7.0$ & 37 & 0.31 & 13.32 & -1.02 & 7.52 & \begin{tabular}{|l|}
0.0022 \\
\end{tabular} \\
\hline 40.0 & 10.91(7) & \begin{tabular}{|l|}
$18.48(8)$ \\
\end{tabular} & $27.60(23)$ & $31.60(5)$ & \begin{tabular}{|l|}
$34.23(9)$ \\
\end{tabular} & $2.0-7.0$ & 104 & 1.26 & \begin{tabular}{|l|l|}
33.74 \\
\end{tabular} & -0.55 & 4.96 & 0.0054 \\
\hline 50.0 & $11.03(4)$ & \begin{tabular}{|l}
$18.56(4)$ \\
\end{tabular} & $27.58(17)$ & $31.65(3)$ & \begin{tabular}{|l|}
$34.55(6)$ \\
\end{tabular} & $2.2-7.0$ & 61 & 0.06 & 9.48 & 0.40 & 4.34 & 0.0025 \\
\hline 60.0 & $11.80(7)$ & $19.49(6)$ & $29.10(27)$ & 33.61(4) & \begin{tabular}{|l|}
$36.73(5)$ \\
\end{tabular} & $2.5-6.5$ & 24 & 0.16 & \begin{tabular}{|l|}
7.33 \\
\end{tabular} & -0.07 & 3.47 & 0.0031 \\
\hline
\end{tabular}

\section{Residual analysis}

In data analysis with least squares method, the residuals (the differences between the experimental data and the data simulated based on model parameters) are assumed to follow the Gaussian distribution. When the data are fit into the models, the residuals should ideally be equal to zero. If statistical measures of the residuals and the errors assumed in the models are not significantly different from each other, the model is said to be adequate. Further, a model is considered adequate only if the residuals do not show any trend. Respecting the hypothesis that the errors are random, the residuals are tested for normal distribution. Such tests are $\chi^{2}$, skewness, kurtosis and R-factor. These statistical parameters show that the best fit models portray the metal-ligand species in Dox-water mixtures. Kurtosis is the measure of the peakedness of the error distribution near a model value. For an ideal normal distribution, kurtosis value should be three (mesokurtic). If the calculated kurtosis is less than three, the peak of the error distribution curve is flat (platykurtic), and if the kurtosis is greater than three, the distribution shall have sharp peak (leptokurtic). The kurtosis values in the present study indicate that some of the residuals are nearer to mesokurtic and others form leptokurtic patterns. The values of skewness (shape of the error distribution profile) recorded in Table 3 are between -0.60 and 1.53 for $\mathrm{Co}(\mathrm{II}),-1.67$ and -0.01 for $\mathrm{Ni}$ (II) and -1.67 and 0.40 for $\mathrm{Cu}(\mathrm{II})$. These data evince that the residuals form a part of the normal distribution. Hence, the least-squares method can be applied to the present data. The low crystallographic R-values given in Table 3 indicate the sufficiency of the model. The Hamilton's R-factor ratio test [37] was developed in crystallographic analysis to decide the need for inclusion of additional terms in the model. The test finds application in complex equilibria to decide whether the inclusion of more species in 
the model is necessary or not. In $\mathrm{pH}$ metric method, the readability of the $\mathrm{pH}$ meter is taken as R-limit, which represents the upper boundary of $\mathrm{R}$ beyond which the model bears no significance. When different values were obtained for models containing different numbers of species, the models whose R-values were greater than R-table values were rejected. These statistical parameters show that the best fit models portray the metal-ligand species in Doxwater media. The order of stability constants was found to be $\mathrm{Co}$ (II) $<\mathrm{Ni}$ (II) $<\mathrm{Cu}$ (II) which is in agreement with Irving-Williams order [38].

\section{Effect of systematic errors on best fit model}

In order to obtain the best chemical model for critical evaluation and application under varied experimental conditions with different accuracies of data acquisition, an investigation was undertaken by introducing pessimistic errors in the influential parameters like concentrations of alkali, mineral acid, ligand and metal (Table 4). The order of the ingredients that influence the magnitudes of stability constants due to incorporation of errors is alkali $>$ acid $>$ ligand $>$ metal. Some species were even rejected when errors were introduced in the concentrations. The rejection of some species and increased standard deviations in the stability constants on introduction of errors confirm the suitability of the experimental conditions (concentrations of ingredients) and choice of the best fit models.

Table 4. Effect of errors in influential parameters on the stability constants of Co(II)-Asp binary complexes in $30 \% \mathrm{v} / \mathrm{v}$ Dox-water mixture.

\begin{tabular}{|c|c|c|c|c|c|c|}
\hline \multirow{2}{*}{\multicolumn{2}{|c|}{ Ingredient }} & \multicolumn{5}{|c|}{$\log \beta_{\mathrm{mlh}}(\mathrm{SD})$} \\
\hline & & ML & $\mathrm{ML}_{2}$ & $\mathrm{ML}_{2} \mathrm{H}_{2}$ & $\mathrm{ML}_{2} \mathrm{H}_{3}$ & $\mathrm{ML}_{2} \mathrm{H}_{4}$ \\
\hline & 0 & $7.51(4)$ & $12.88(6)$ & $25.26(5)$ & $29.34(7)$ & $33.01(8)$ \\
\hline \multirow{4}{*}{ Alkali } & -5 & rejected & rejected & $24.42(40)$ & 29.73(44) & $34.09(27)$ \\
\hline & -2 & $7.90(36)$ & $7.44(28)$ & $25.04(25)$ & $29.99(16)$ & $33.79(13)$ \\
\hline & +2 & $8.51(60)$ & $11.39(60)$ & $29.36(60)$ & $32.87(59)$ & $36.46(59)$ \\
\hline & +5 & rejected & $22.04(* *)$ & $39.24(* *)$ & $42.33(* *)$ & $45.59(* *)$ \\
\hline \multirow{4}{*}{ Acid } & -5 & rejected & 21.59 (**) & $38.99(* *)$ & 42.39 (**) & $45.17(* *)$ \\
\hline & -2 & $14.77(60)$ & $18.53(* *)$ & $36.26(* *)$ & $39.72(* *)$ & $42.95(* *)$ \\
\hline & +2 & $9.89(61)$ & $12.55(61)$ & $31.11(61)$ & $34.87(61)$ & $38.44(61)$ \\
\hline & +5 & $3.49(22)$ & $5.96(20)$ & $25.37(15)$ & $29.91(15)$ & $33.69(11)$ \\
\hline \multirow{4}{*}{ Ligand } & -5 & $5.33(17)$ & $8.19(14)$ & $26.63(12)$ & $30.33(16)$ & $34.19(11)$ \\
\hline & -2 & $5.24(16)$ & $7.89(14)$ & $26.69(12)$ & $30.61(13)$ & $34.35(12)$ \\
\hline & +2 & $4.95(15)$ & $7.39(15)$ & $26.72(12)$ & $30.93(12)$ & $34.61(11)$ \\
\hline & +5 & $8.61(* *)$ & rejected & $30.68(* *)$ & $35.62(* *)$ & $39.07(* *)$ \\
\hline \multirow{4}{*}{ Metal } & -5 & $5.44(16)$ & $8.00(16)$ & $26.96(16)$ & $30.99(16)$ & $34.68(16)$ \\
\hline & -2 & $5.28(15)$ & $7.81(13)$ & $26.82(11)$ & $30.86(12)$ & $34.55(10)$ \\
\hline & +2 & $5.12(16)$ & $7.59(15)$ & $26.66(12)$ & $30.72(13)$ & $34.42(12)$ \\
\hline & +5 & $5.07(15)$ & $7.46(14)$ & $26.57(11)$ & $30.64(12)$ & $34.34(11)$ \\
\hline
\end{tabular}

** High standard deviation.

Effect of co-solvent

Co-solvent influences the protonation-deprotonation equilibria in solution by changing the dielectric constant of the medium, which varies the relative contributions of electrostatic and non-electrostatic interactions. So the variation of $\log \mathrm{K}^{\mathrm{M}}$ or change in free energy with cosolvent content depends upon electrostatic and non-electrostatic interactions and can be represented as the sum of the changes in $\Delta \mathrm{G}$ due to these two factors (Eq. 1). 
$\Delta \mathrm{G}=-\mathrm{RT}\left(\ln \mathrm{K}^{\mathrm{M}}-\ln \mathrm{K}^{\mathrm{W}}\right)=\Delta \mathrm{G}_{\mathrm{el}}+\Delta \mathrm{G}_{\mathrm{nel}}$

where $\mathrm{K}^{\mathrm{W}}$ and $\mathrm{K}^{\mathrm{M}}$ are the step-wise protonation constants in aqueous and in aquo-organic mixtures, respectively.

Born's classical treatment [39] holds good in accounting for the electrostatic contribution to the free energy change $\left(\Delta \mathrm{G}_{\mathrm{el}}\right)$. According to this treatment, an ion of charge $\mathrm{Ze}$ is considered to be a rigid sphere of radius, $r$ and the energy of electrostatic interaction is related to macroscopic dielectric constant, D of the medium as given by Eq. 2 .

$\Delta \mathrm{G}_{\mathrm{el}}=\frac{\mathrm{Ne}^{2}}{2} * \frac{1}{\mathrm{D}} * \frac{1}{\mathrm{r}}$

Eqs. 1 and 2 suggest that $\log \beta$ should vary linearly as a function of reciprocal of the dielectric constant (1/D) of the medium. The change in dielectric constant varies the relative contribution of electrostatic and non-electrostatic interactions which in turn vary the magnitudes of stability constants. If the electrostatic forces alone operate, $\log \mathrm{K}^{\mathrm{M}}$ should vary linearly as a function of $1 / \mathrm{D}$ of the medium. Such linear variation in the stability constant $(\log \beta)$ values of complexes of Asp with $\mathrm{Co}(\mathrm{II}), \mathrm{Ni}$ (II) and $\mathrm{Cu}$ (II) with variation of $1 / \mathrm{D}$ (D is the dielectric constant of the medium) of Dox-water mixtures (Figure 1) indicates the dominance of electrostatic interactions. In the case of some mono- and di-carboxylic acids and simple phenolic ligands, electrostatic (long-range, non-specific or universal) solute-solvent interactions are predominant in binary mixtures of water with methanol, ethanol, dioxan or acetone as co-solvent.

A

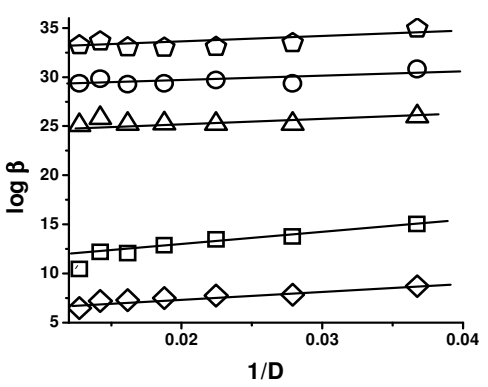

C

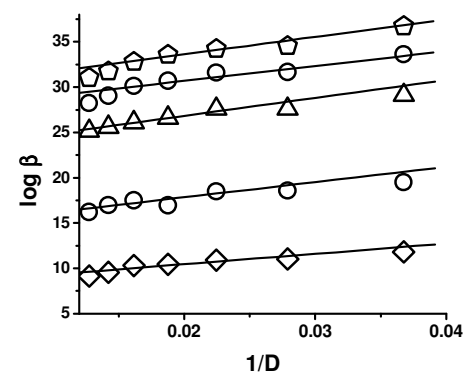

\section{B}
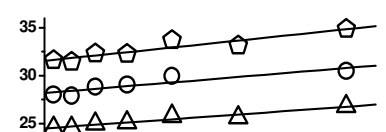

$\stackrel{0}{20}$

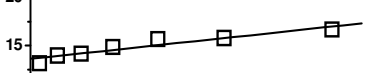

10 -

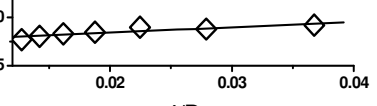

1/D

Figure 1. Variation of stability constant values of metal-Asp complexes with reciprocal of dielectric constant (1/D) of Dox: (A) Co(II); (B) Ni(II); (C) Cu(II)-( $\diamond) \log \beta \mathrm{ML}$; ( $\square$ ) $\log \beta \mathrm{ML}_{2} ;(\Delta) \log \beta \mathrm{ML}_{2} \mathrm{H}_{2} ;(\circ) \log \beta \mathrm{ML}_{2} \mathrm{H}_{3} ;(\triangle) \log \beta \mathrm{ML}_{2} \mathrm{H}_{4}$. 
Even though the solvent (Dox) has low dielectic constant it was chosen such that Dox-water mixture is the combination of aprotic and protic solvents with wide range of dielectric constants and with good solubility for polar as well as non-polar solutes. The cosolvent induced increased basicity [40] of Dox-water mixtures, increases the stabilization of protons. At the same time the coordinating solvent (Dox) competes with the ligands for coordination with the metals. This decreases the stability of the complexes. Hence, the stability of the complex is expected to either increase or decrease.
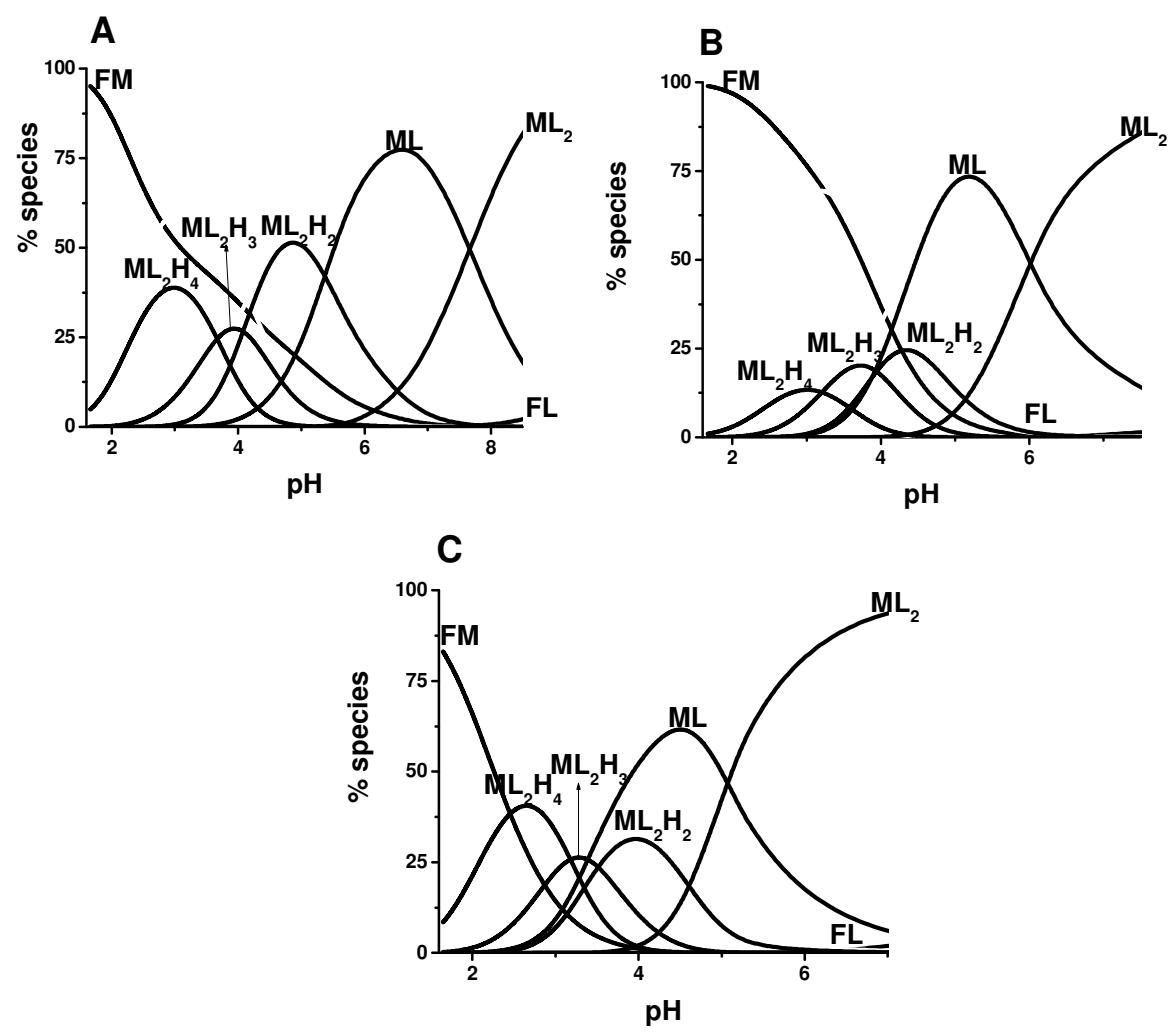

Figure 2. Species distribution diagrams of binary complexes of Aspartic acid in 30\% v/v DoxWater mixture. (A) $\mathrm{Co}(\mathrm{II})$; (B) $\mathrm{Ni}(\mathrm{II})$; (C) $\mathrm{Cu}$ (II).

\section{Distribution diagrams}

Asp has two dissociable protons and its form is $\mathrm{LH}_{3}{ }^{+}$at low $\mathrm{pH}$. It gets deprotonated to the formation of $\mathrm{LH}_{2}, \mathrm{LH}^{-}$and $\mathrm{L}^{2-}$ successively with increasing $\mathrm{pH}$. The models refined are ML, $\mathrm{ML}_{2}, \mathrm{ML}_{2} \mathrm{H}_{2}, \mathrm{ML}_{2} \mathrm{H}_{3}$ and $\mathrm{ML}_{2} \mathrm{H}_{4}$ species for $\mathrm{Co}(\mathrm{II}), \mathrm{Ni}$ (II) and $\mathrm{Cu}$ (II) in Dox-water mixtures. Typical species distribution diagrams of Asp complexes are given in Figure 2. The formation of various binary complexes is shown in the following equilibria: 


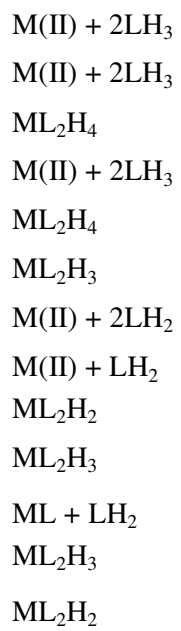

$\begin{array}{ll}\rightleftharpoons & \mathrm{ML}_{2} \mathrm{H}_{4}+2 \mathrm{H}^{+} \\ \rightleftharpoons & \mathrm{ML}_{2} \mathrm{H}_{3}+3 \mathrm{H}^{+} \\ \rightleftharpoons & \mathrm{ML}_{2} \mathrm{H}_{3}+\mathrm{H}^{+} \\ \rightleftharpoons & \mathrm{ML}_{2} \mathrm{H}_{2}+4 \mathrm{H}^{+} \\ \rightleftharpoons & \mathrm{ML}_{2} \mathrm{H}_{2}+2 \mathrm{H}^{+} \\ \rightleftharpoons & \mathrm{ML}_{2} \mathrm{H}_{2}+\mathrm{H}^{+} \\ \rightleftharpoons & \mathrm{ML}_{2} \mathrm{H}_{2}+2 \mathrm{H}^{+} \\ \rightleftharpoons & \mathrm{ML}+2 \mathrm{H}^{+} \\ \rightleftharpoons & \mathrm{ML}+\mathrm{LH}+\mathrm{H}^{+} \\ \rightleftharpoons & \mathrm{ML}+\mathrm{LH}^{2}+2 \mathrm{H}^{+} \\ \rightleftharpoons & \mathrm{ML}_{2}+2 \mathrm{H}^{+} \\ \rightleftharpoons & \mathrm{ML}_{2}+3 \mathrm{H}^{+} \\ \rightleftharpoons & \mathrm{ML}_{2}+2 \mathrm{H}^{+}\end{array}$

Equilibria 1-13 indicate the formation of $\mathrm{ML}, \mathrm{ML}_{2}, \mathrm{ML}_{2} \mathrm{H}_{2}, \mathrm{ML}_{2} \mathrm{H}_{3}$ and $\mathrm{ML}_{2} \mathrm{H}_{4}$. Figure $3 \mathrm{~A}$ represents the formation of Co-Asp complexes. $\mathrm{ML}_{2} \mathrm{H}_{4}$ is formed by the interaction of free metal ion (FM) with $\mathrm{LH}_{3}{ }^{+}$(Equilibrium 1). Similarly $\mathrm{ML}_{2} \mathrm{H}_{3}$ is formed by the interaction of free metal with $\mathrm{LH}_{3}{ }^{+}$(Equilibrium 2) as well as by the deprotonation of $\mathrm{ML}_{2} \mathrm{H}_{4}$ (Equilibrium 3). Deprotonated species $\mathrm{ML}_{2}$ and $\mathrm{ML}$ are formed beyond a $\mathrm{pH}$ of 4.0 (Equilibria 8-13). Figure 3B shows the formation of $\mathrm{Ni}$-Asp complexes. $\mathrm{ML}_{2}$ is the most predominant species among all. The concentration of $\mathrm{ML}_{2} \mathrm{H}_{2}$ species decreased while the concentration of $\mathrm{ML}$ and $\mathrm{ML}_{2}$ increased in the $\mathrm{pH}$ range 5.0-7.5 indicatig their formation from $\mathrm{ML}_{2} \mathrm{H}_{2}$ (Equilibria 9 and 13). Figure 3C shows the formation of $\mathrm{Cu}-\mathrm{Asp}$ complexes in the $\mathrm{pH}$ range 2.0-7.0.

\section{Structures of complexes}

Based on the above equilibria the possible structures of the binary complexes of Asp are given in Figure 3. The literature [41, 42] suggests that $\mathrm{Co}(\mathrm{II}), \mathrm{Ni}(\mathrm{II})$ and $\mathrm{Cu}$ (II) complexes shall be octahedral or distorted octahedral. Amino nitrogen and carboxyl oxygen of Asp participate in bonding with the metal ions.

\section{CONCLUSIONS}

The following conclusions have been drawn from the modelling studies of the speciation of binary complexes of $\mathrm{Co}(\mathrm{II}), \mathrm{Ni}(\mathrm{II})$ and $\mathrm{Cu}(\mathrm{II})$ with L-Asp in Dox-water mixtures: (1) L-Asp forms both protonated and unprotonated complexes $\mathrm{ML}, \mathrm{ML}_{2}, \mathrm{ML}_{2} \mathrm{H}_{2}, \mathrm{ML}_{2} \mathrm{H}_{3}$ and $\mathrm{ML}_{2} \mathrm{H}_{4}$ in the $\mathrm{pH}$ range 1.85-10.5. (2) The linear variation of stability constants as a function of dielectric constant of the medium indicates the dominance of electrostatic forces over non-electrostatic forces. Some species are stabilized due to electrostatic interactions and some are destabilized due to the decreased dielectric constant. (3) The order of ingredients influencing the magnitudes of stability constants due to incorporation of errors in their concentrations is alkali $>$ acid $>$ ligand $>$ metal. (4) The stabilities of the complexes follow the Irving-Williams order, i.e. Co(II) $<\mathrm{Ni}$ (II) $<\mathrm{Cu}($ II) . 


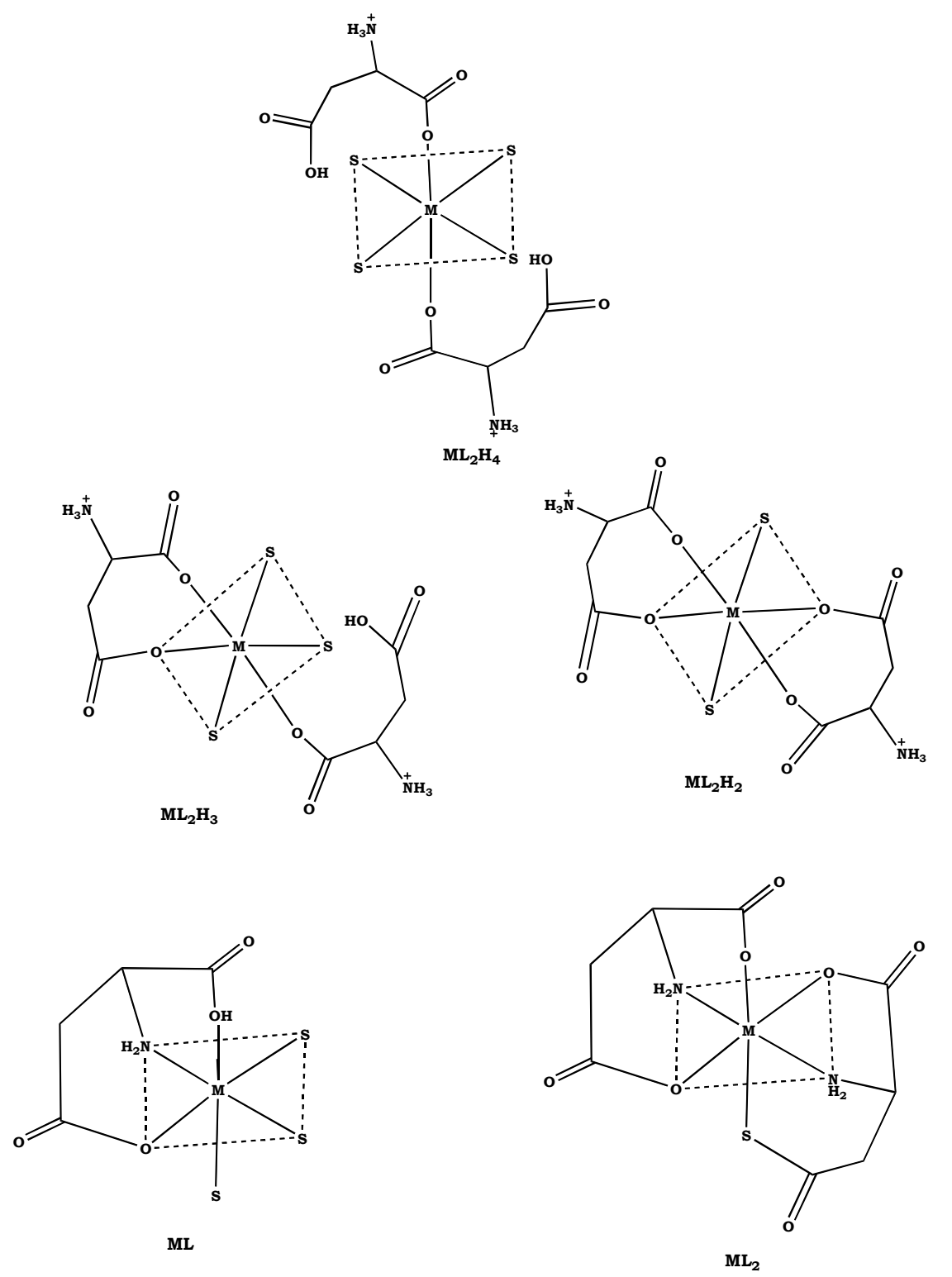

Figure 3. Structures of Asp complexes where $\mathrm{S}$ is either solvent or water molecule.

\section{REFERENCES}

1. Philip, E.C.; Matthew, T.G.; Phillip, J.S.; Alexander, R.J.; Hongjie Y.; Amanda L.J.; James, P.S.; Stephen, F.T.; David, J.A.W. Mol. Pharmacol. 2005, 67, 1470.

2. Martel, A.E. Critical Stability Constants of Metal Complexes, Plenum Press: New York; 2006; $p 26$. 
3. Ritchie, S.M.C.; Bachas, L.G.; Olin, T.; Sikdar, S.K.; Bhattacharyya, D. Langmuir. 1999, $15,6346$.

4. Pasquale, M.Di. Amino Acids and Proteins for the Athlete the Anabolic Edge, CRC Press: Boca Raton; 1997, p 130.

5. Sigel, H.; Martin, R.B.; Tribolet, R.; Haring, U.K.; Balakrishnan, R.M. Eur. J. Biochem. 1985, 152, 187.

6. May, P.M.; Linder, P.W.; Williams, D.R. J. Chem. Soc. Dalton Trans. 1977, 588.

7. Kumar, N.V.; Rao, G.N. Acta Chim. Slov. 2011, 58, 342.

8. Ramaraju, B.; Devi, K.V.S.; Rao, G.N. IUP J. Chem. 2011, 4, 7.

9. Rao, V.S.; Rao, P.S.; Srikanth, B.; Sastry, C.K.; Rao, G.N. Bull. Chem. Soc. Ethiop. 2009, $23,347$.

10. Lavanya, K.V.; Rao, V.M.; Rao, G.N. Oxidat. Commun. 2008, 31, 398.

11. Latha, M.P.; Rao, V.M.; Rao, T.S.; Rao, G.N. Bull. Chem. Soc. Ethiop. 2007, 21, 363.

12. Rao, G.N.; Sudarsan, K.G. Chem. Speciat. Bioavail. 2006, 18, 71.

13. Rao, G.N.; Ramakrishna, A. Proc. Nat. Acad. Sci. India. 2005, 75, 245.

14. Kumar, N.V.; Sreekanth, B.; Rao, G.N. Bull. Chem Soc. Ethiop. 2012, 26, 239.

15. Rao, V.S.; Rao, P.S.; Srikanth, B.; Sastry, C.K.; Rao, G.N. Chem. Speciat. Bioavail. 2009, 2,71 .

16. Lumb, R.F.; Martell, A.E. J. Phys. Chem. 1953, 57, 690.

17. Vadi, M.; Zare, Z.; Nasiri, Kh. Russ. J. Inorg. Chem. 2007, 52, 816.

18. Gianguzza, A.; Pelizzetti, E.; Sammartano, S. Chemistry of Marine Water and Sediments, 2nd ed., Springer: Berlin; 2002; p 337.

19. Ritsma, J.H. Rec. Trav. Chim. 1975, 94210.

20. Maker, G.K.R.; Touche, M.L.D.; Williams, D.R. J. Chem. Soc. 1976, 1016.

21. Gergely, A.; Farakas, E.; Magy. Kem. Foly. 1975, 81, 471.

22. Gergely, A.; Nagypal, I.; Farakas, E. Acta Chim. Acad. Sci. Hung. 1974, 82, 43.

23. Gergely, A.; Nagypal, I.; Farakas, E. Magy. Kem. Foly. 1974, 80, 56.

24. Heijne, G.J.H.; van der Linden, W.E. Talanta 1975, 22, 923.

25. Sarin, R.; Munshi, K.N. J. Inorg. Nucl. Chem. 1972, 34, 581.

26. Kulba, F.Y.; Ushakova, V.G.; Yakovlev, Y.B. Russ. J. Inorg. Chem. 1975, 20, 43.

27. Kodama, M.; Takahashi, S. Bull Chem. Soc. Jpn. 1971, 44, 697.

28. Gran, G. Anal. Chim. Acta 1988, 206, 111.

29. Gran, G. Analyst 1952, 77, 661.

30. Rao, R.S.; Rao, G.N. Computer Applications in Chemistry, Himalaya Publishing House: Mumbai; 2005; p 227.

31. Van Uitert, L.G.; Fernelius, W.C. J. Am. Chem. Soc. 1954, 76, 5888.

32. Rao, G.N. Complex equilibria of biological importance in aquo-organic media - computer augmented modeling studies, Ph.D. Thesis, Andhra University, Visakhapatnam, India, 1989, p 244.

33. Gans, P.; Sabatini, A.; Vacca, A. Inorg. Chim. Acta 1976, 18, 237.

34. Chandraleela, A.; Rani, R.S.; Rao, G.N. Proc. Natl. Acad. Sci. India 2012, 82, 197.

35. Vadi, M.; Zare, Z; Nasiri, Kh. Russ. J. Inorg. Chem. 2007, 52, 816.

36. Alexey, O.; David, A.; Ullman, G.M. Biochem. 2001, 40, 3413.

37. Hamilton, W.C. Acta Cryst. 1965, 18, 502.

38. Irving, H.M.N.H.; Williams, R.J.P. J. Chem. Soc. 1953, 3192.

39. Born, M.Z. Phys. 1920, 1, 45.

40. Rao, G.N.; Rao, R.S. J. Teach. Res. Chem. 1995, $2,15$.

41. Jamie, A.G.; Matthew, J.R.; Stephen, A.M. Dalton Trans., 2012, 41, 5464.

42. Larin, G.M.; Shul'gin, V.F. Russ. J. Inorg. Chem. 2006, 51, 28. 